\title{
A inexistência de ordem V-S no português brasileiro
}

\author{
Eunice Nicolau \\ Universidade Federal de Minas Gerais
}

\section{Abstract}

The paper examines the occurrence of post-verbal DP in inacusative sentences, which is traditionally treated as the V-S Order and still presented in BP. Assuming the Minimalist program (CHOMSKY, 1995) and ZUBIZARRETTA (1995), this paper proposes that in BP: i) the sentences treated, in the literature, as case of V-S Order are constructed based on a Numeration containing [-accusative] verb and an element specified by the $[+F]$ trace, from which results an Apresentative structure; ii) in BP the [-accusative] DP generated in the inner position of $\mathrm{V}$ and specified with $[+\mathrm{F}]$ feature stays in that position, where it receives the main stress of the sentence so that it is a Nominative Object; iii) the inacusative sentences, which are traditionally regarded as having the V-S Order, leave the SVO structure. Therefore there is no possibity of treating them as the $\mathrm{V}-\mathrm{S}$ Order in BP. 


\section{PRELIMINARES}

A partir da proposta de CHOMSKY (1981) de que a marcação positiva do parâmetro pro-drop teria como conseqüência um 1 conjunto de propriedades sintáticas, os pressupostos fornecidos pela Teoria Gerativa são invocados por inúmeros estudos na tentativa de se explicar uma dessas propriedades, que, segundo o referido autor, consiste na inversão livre do sujeito e se faz presente em dois tipos de estrutura:

A) uma estrutura que resulta da aplicação de Mova-a, ou seja, de uma regra de movimento do sujeito para a posição de adjunção ao VP, como representado por (1b), abaixo:

(1) a. telefonano molti studenti (CHOMSKY, 1981, p. 260, (18i))

b. $\left[_{\mathrm{S}}\right.$ PRO $\left[_{\mathrm{VP}}\left[{ }_{\mathrm{VP}}\right.\right.$ telefon-AGR] $\left[_{\mathrm{NP}}\right.$ molti studenti $\left.\left.]\right]\right]$ (CHOMSKY, 1981, p.261, (21))

B) uma estrutura que resulta da aplicação de uma regra de subida do verbo para Infl, em que o sujeito é gerado (e permanece) na posição de objeto de um verbo ergativo, como ilustra (2b):

(2) a. arrivano molti studenti (CHOMSKY, 1981, p. 260, (18ii))

a. [S PRO [ ${ }_{\mathrm{VP}}$ arriv-AGR [ ${ }_{\mathrm{NP}}$ molti studenti]]] (CHOMSKY, 1981, p. 261, (22))

Para SHLONSKY (1988), a sentença (2a) apresenta uma estrutura que inclui verbos inacusativos e passivos, na qual, o sujeito está numa posição interna a VP (na verdade, interna a V), mas a sentença (1a) apresenta uma estrutura com o sujeito em adjunção a VP e essa estrutura pode conter verbo inergativo (caso de "inversão 
livre") ou verbo transitivo (caso de inversão "provocada"). Ainda de acordo com o referido autor, nesse último caso (de inversão "provocada"), a ordem derivada é VSO, e isso significa que:

i) o sujeito é, conforme propõe SHLONSKY (1987), adjungido à esquerda de VP, como mostra a representação (3a):

(3) a. Sujeito adjungido à esquerda de VP => VSO (cf. SHLONSKY, 1987, apud SHLONSKY, 1988)

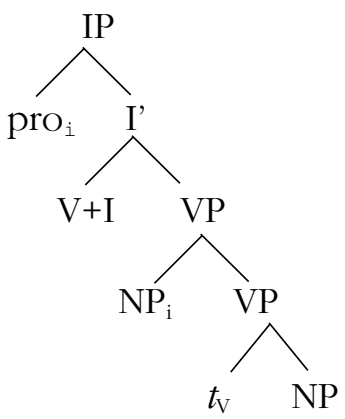

ii) o sujeito não é, portanto, adjungido à direita de VP conforme defendem KAYNE e POLLOCK (1978), que chamam essa inversão de "estilística" - da adjunção do sujeito a VP resultaria a ordem VOS, como mostra a representação (3b):

(3) b. Sujeito adjungido à direita de VP => VOS (cf. KAYNE e POLLOCK, 1978)

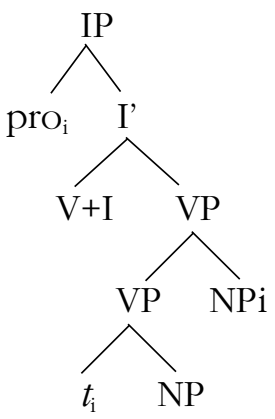


A hipótese de KAYNE \& POLLOCK (1978) de que, em construções com inversão estilística, o NP sujeito se desloca para a direita, ou seja, o sujeito é deslocado de sua posição de base para uma posição de adjunção a VP ou a IP, é também rejeitada por ÂMBAR (1988), que examina as construções com Inversão Sujeito/Verbo no português europeu (PE). Na opinião dessa autora, tal hipótese não explica a ordem VSO, encontrada em frases como as de (4), a seguir, pois o movimento do NP para a direita (ou "estratégia de descida do SN"), nesses casos, implicaria o NP ter, como destino, uma posição no interior de VP, o que é excluído pela teoria do movimento como formulada em CHOMSKY (1986):

(4) a. O que ofereceu o Pedro à Joana?

b. Onde pôs o João os quadros?

c. A quem ofereceste tu as flores?

E, segundo ÂMBAR, no PE, a ordem básica é SVO (que é a única a apresentar uma combinação nua dos elementos S, V e O), mas as seis ordens com verbos transitivos possíveis nas línguas são todas permitidas, conforme ilustram as sentenças de (5):

(5)
a. A Joana comeu a sopa.
(SVO)
b. A sopa, a JOANA comeu.
(OSV)
c. A Joana, a sopa, comeu.
(SOV)
d. Ontem comeu a Joana a sopa.
(VSO)
e. Comeu a sopa, a Joana.
(VOS)
f. A sopa, comeu a Joana.
(OVS)

No português brasileiro (PB), diferentemente do que se verifica no PE, em sentenças com verbo transitivo, nem a ordem VOS - ou seja, a chamada inversão estilística ou românica - é permitida, o que explica a agramaticalidade das sentenças de (6):

(6) a. * Ontem comeram as crianças o bolo.

(VSO)

b. *Comeram o bolo, as crianças.

(VOS)

c. *O bolo, comeram as crianças. 
O fato de o PB não permitir a ordem verbo-sujeito (doravante, ORDEM V-S) em sentença com verbo transitivo tem sido, consistentemente, atestado por estudos variacionistas (LIRA, 1982, 1986; BERLINCK, 1994; etc.) e assumido por análises realizadas à luz da Teoria Gerativa (BITTENCOURT,1979; NASCIMENTO,1984; TARALLO \& KATO, 1989; FIGUEIREDO SILVA,1994; etc.). Em síntese, o fenômeno que vem sendo tratado como ORDEM V-S no PB figura apenas em sentenças com verbos não-marcadores do caso acusativo, isto é, consiste na ocorrência de um DP que não tem o caso acusativo (abreviadamente, DP[-acus]), em posição pós-verbal.

As análises desse fenômeno sob a perspectiva da Gramática Gerativa, mais exatamente, da Teoria da Regência e Ligação (TRL), têm lhe atribuído diferentes explicações (e, por conseqüência, diferentes denominações: posposição do sujeito, inversão do sujeito, fronteamento do verbo, etc.), assumindo que o licenciamento do DP[-acus] pós-verbal é determinado apenas por fatos relativos a marcação de caso. Mas essas mesmas análises, além de atestarem que o caso do DP[-acus] pós-verbal, o estatuto desse DP e a estrutura das sentenças nas quais esse DP é licenciado continuam sendo motivo de controvérsias, revelam (explícita ou implicitamente) a intuição de que a solução para a questão do caso do DP[-acus] pós-verbal não é suficiente para se explicar o fenômeno chamado de ORDEM V-S no PB.

A proposta de NASCIMENTO (1984) - para quem, a inversão do sujeito no PB não passa de um processo de formação de frases apresentativas, que exclui os verbos transitivos - prevê que todas as frases apresentativas veiculam um conteúdo semântico que exclui o NP universalmente quantificado da posição pós-verbal de sentenças como (7a) e explica o licenciamento, nesse contexto, de diversos tipos de NP que permitem interpretação de lista, tais como $(7 \mathrm{~b}, \mathrm{c})$ :

(7) a. Viajaram várias moças.

b. NP contendo relativa restritiva: Correu um/o carro de que todos falavam.

c. NP de descrição definida: Havia na mesa uma/a faca de cortarpão. 
Enfim, de acordo com o referido autor, o DP [-acus] pós-verbal (analisado como sujeito) recebe o nominativo, mas há uma restrição semântica imposta à sua ocorrência: o contexto que permite interpretação de lista.

A análise de FIGUEIREDO SILVA (1994), segundo a qual, esse DP (analisado como sujeito invertido) é marcado partitivo inclui uma outra restrição: o Efeito de Definitude (o que deixa não-explicadas as ocorrências, em posição pós-verbal, de DP definido seguido de outros sintagmas). A proposta de NASCIMENTO \& KATO (1995) de que o Filtro do Caso não atinge o N' (contido no DP e analisado como predicado de mini-oração complemento) inclui, além da "Restrição de Definitude", mais uma restrição: o acento contrastivo (típico de foco) dos nominais definidos que seguem verbos inacusativos.

Essa última restrição - que é também mencionada por KATO (1993), segundo a qual, há indício de que, na construção com a ORDEM V-S em que o sujeito permanece dentro do VP (inversão inacusativa), esse sujeito é um NP focal - remete à análise atribuída por RAPOSO \& URIAGEREKA (1990) a sentenças inacusativas do PE e que, como será visto mais adiante, ressalta um fato já apontado na análise de BELLETTI (1988), ou seja, o fato de que o DP[-acus] pósverbal é licenciado apenas em sentenças que incluem determinadas relações semânticas.

A ocorrência de DP[-acus] pós-verbal continua sendo uma preocupação no estágio mais recente da Teoria Gerativa. Na opinião de BRANIGAN (1992), no inglês, a exigência de checagem do traço$\mathrm{D}$ de $\mathrm{T}$ (postulada por CHOMSKY, 1993) envolve o referido DP, que se move para o Espec/TP (onde tem checado o seu traço Caso) em FL e permanece no interior do VP em FF. Para CHOMSKY (1995), tal checagem implica a presença do expletivo There, não-especificado quanto ao caso, uma vez que o traço Marcar Caso Nominativo de T é checado através do movimento implícito dos traços do DP pós-verbal. Essas duas análises apresentam um ponto em comum: a falta de uma razão para o fato de o movimento explícito do DP para o Espec/TP, excepcionalmente, deixar de ocorrer apenas em construções inacusativas. 
O problema das duas últimas análises acima mencionadas, embora não seja sequer colocado na literatura gerativa, parece ser o de crucial importância para a explicação da possibilidade, ou não, de ocorrência de DP[-acus] pós-verbal. Em síntese, diante das várias propostas de explicação para o licenciamento de DP[-acus] em posição pós-verbal encontradas na literatura, torna-se, pois, evidente que a questão crucial a ser respondida em relação ao referido fenômeno não é relativa a caso (marcação/não-marcação ou checagem) mas, sim, a que pode ser, em termos minimalistas, assim formulada:

(8) Por que, em determinadas sentenças com verbos inacusativos, o DP[-acus], tradicionalmente analisado como sujeito, não se move para a posição de Espec/TP a fim de se envolver na checagem do traço-D de T e ocorre em posição pós-verbal?

Com o objetivo de responder a essa questão, o presente trabalho analisa a ocorrência de DP[-acus] pós-verbal no PB (tradicionalmente tratada como ORDEM V-S), a partir da hipótese de que as sentenças do tipo (9b), abaixo, resultam de derivações que não se explicam por exigência do Filtro do Caso; mais exatamente, a partir da hipótese de que as sentenças do tipo (9b), que, nos moldes minimalistas (CHOMSKY, 1993 e 1995), envolvem numerações diferentes das envolvidas na construção das sentenças do tipo (9a), resultam de derivações que se explicam por razões de natureza semântica.

(9) a. A carta chegou.

b. Chegou a carta.

O estudo contém mais três seções: a seção 2 compara dados do PB a dados do PE, destacando as distinções entre essas duas modalidades do português quanto a condições impostas à ocorrência de DP pós-verbal em sentenças inacusativas; a seção 3 apresenta uma alternativa de análise para as sentenças com DP[-acus] pós-verbal do $\mathrm{PB}$, na qual se assume que o licenciamento desse DP não é determinado pelo Filtro do Caso, ou seja, propõe-se, com base em alguns pressupostos minimalistas (CHOMSKY, 1995) e seguindo 
ZUBIZARRETTA (1995), que a posição a ser ocupada pelo DP argumento de verbos inacusativos é determinada pelas propriedades dos itens envolvidos na construção de sentenças com tais verbos; a seção 4 busca ressaltar o fato de que as sentenças inacusativas do PB nas quais o DP figura em posição pós-verbal - tradicionalmente apontadas na literatura como aquelas que ainda exibem a ORDEM V-S - apresentam estrutura SVO e, assim sendo, a possibilidade de ORDEM V-S, no PB, inexiste.

\section{OS DADOS DO PB COMPARADOS AOS DADOS DO PE}

Ao tratarem do caso do DP pós-verbal de sentenças inacusativas e passivas do PE, RAPOSO \& URIAGEREKA (doravante, R\&U) fazem afirmações, em relação a tais sentenças, com base em argumentos que, como mostram os próximos parágrafos, não são corroborados pelos dados do PB:

I - A substituição do NP indefinido por pronome nominativo evidencia que, como postula BELLETTI, não há nominativo no objeto temático in situ, marcado com o partitivo:

(10) a. Chegou $\left[_{\mathrm{NP}}\right.$ um estudante] tarde. (R\&U: (4a))

a'. ":Chegou ele tarde.

b. Foi convidado $\left[_{\mathrm{NP}}\right.$ um estudante] para a festa.(R\&U: (4b))

b'. "?Foi convidado ele para a festa.

Como ilustram as sentenças de (11), a seguir, desde que seja atribuído um acento contrastivo (doravante, sinalizado pelo uso de maiúsculas) ao DP pós-verbal das sentenças (11a, b), o PB admite a substituição dos DPs indefinidos por DPs definidos nessa posição:

(11) a. Chegou O ESTUDANTE tarde. (e não o professor)

b. Foi convidado O ESTUDANTE para a festa. (e não o professor)

Além disso, sentenças do tipo das assinaladas em (10) como agramaticais no PE são aceitas tranqüilamente em dialetos não- 
padrão do $\mathrm{PB}$, se o pronome nominativo recebe o acento contrastivo, como mostram os exemplos seguintes:

(12) a. Agora, chegou ElE (e não o Pedro, ou o João, etc.).

b. Foi visto ELE na garage (e não eu, ou o João, etc.).

II - A substituição do NP sujeito não-alçado de Mini-Oração (MO) adjetival-complemento de construções inacusativas e passivas por pronome nominativo mostra que, nesse NP, não há nominativo:

(13) a. "Em Beirute, [e] ficaram ontem I $_{\mathrm{MO}}$ esses soldados feridos]. (R\&U: (8a))

b. "Em Beirute, ficaram [eles feridos]. (R\&U: (17))

A observação relativa às sentenças de (10) é válida também para essas sentenças de (13), que, no PB, são perfeitamente boas se recebem uma leitura contrastiva, como em (14):

(14) a. Em Beirute, ficaram ESSES SOLDADOS feridos (mas não todos). b. Em Beirute, ficaram ELES feridos (mas não nós).

III - Na construção inacusativa ou passiva, o NP sujeito não-alçado de MO-preposicional-complemento recebe o nominativo, pois: (i) a substituição do NP definido por NP indefinido mostra que não há aí o Efeito de Definitude - esse NP não é, pois, marcado com o partitivo, o que se verifica em (15); (ii) o acusativo não exerce qualquer papel no licenciamento desse NP, como mostra (16); (iii) a substituição do NP por pronome nominativo resulta em estruturas gramaticais, como (17):

(15) a. Em Beirute, ficaram ontem $\left[_{\mathrm{MO}}\right.$ esses soldados sem armas] (R\&U: (9a))

b. Em Beirute, ficaram ontem $\left[_{\mathrm{MO}}\right.$ ? alguns soldados sem armas] (R\&U: NOTA:ia)

(16) a. Continuava o meu amigo sem assistência médica. (R\&U: (32))

b. *Continuava-o sem assistência médica. (R\&U: NOTA:i) 
(17) a. Ficaram [esses soldados sem armas] (R\&U: (9a))

b. Ficaram [eles sem armas] (R\&U: (15))

Quanto à parte (i) dessa afirmação III, cabem duas observações: em primeiro lugar, na medida em que o caso partitivo implica atuação do Efeito de Definitude, não se justifica a substituição ilustrada em (15b) com o objetivo de se evidenciar a não-marcação do partitivo no DP pós-verbal de (15a), que é definido; em segundo lugar, na verdade, a sentença (15a) aponta para o fato de que o Efeito de Definitude não interfere no licenciamento do DP pós-verbal de todas as estruturas inacusativas do PE; ou seja, o contraste entre (13a) e (15a) evidencia que, no PE, o DP definido pós-verbal não é permitido em estruturas inacusativas do tipo [(X) V-DP-AP], mas pode ocorrer em estruturas inacusativas do tipo [(X) V-DP-PP].

A parte (ii) da afirmação é indiscutível e pode ser estendida às outras sentenças de (10), conforme atestam os dados de (18):

(18) a. "?Chegou-o tarde.

b. "Foi convidado-o para a festa.

c. *Em Beirute, ficaram-nos feridos.

No entanto, a parte (iii) da afirmação aponta para a objeção colocada ao argumento da afirmação I, pois, no PB:

$1^{\circ}$ ) As sentenças de (17) associam-se à estrutura (19), abaixo, sse, o DP pós-verbal recebe acento contrastivo, como em (20a), e pode ser substituído pelo pronome nominativo:

(19) [ficar [X [sem armas ]]]

(20) a. Ficaram OS/ESSES SOLDADOS sem armas.(os generais/os outros não)

b. Ficaram ELES sem armas. (e, não, nós)

2) A seqüência (20a), sem o acento contrastivo, é interpretada como uma sentença na qual ficar significa não $\operatorname{ir}$ (a/para algum lugar); o PP restringe o conjunto (no todo ou em parte) de 
soldados que não tinham armas e, se apenas a seqüência os soldados é substituída pelo pronome, a frase é agramatical:

(21) a. Ficaram os/esses soldados sem armas. (Os soldados com armas partiram)

b. Ficaram eles $/{ }^{*}$ Ficaram eles sem armas.

$3^{\circ}$ ) o observado em relação a (17) e a (20a) estende-se às sentenças com DP indefinido:

(22) a. Ficaram ALGUNS SOLDADOS sem armas. (nem todos; outros, não)

b. Ficaram ELES sem armas. (e, não, nós/vocês)

$\Rightarrow$ [ficaram [Alguns soldados/eles $\left[_{\mathrm{PP}}\right.$ sem armas]]]

(23) a. Ficaram alguns soldados sem armas. (Os soldados com armas partiram)

b. Ficaram eles $/ *$ Ficaram eles sem armas

Os dados (11) e (12) permitem afirmar que, no PB: de um lado, o Efeito de Definitude não interfere no licenciamento do NP [-acus] pós-verbal - tal licenciamento não pode, portanto, ser explicado em termos de marcação de partitivo; de outro lado, a substituição de um DP definido por um pronome nominativo não implica agramaticalidade da sentença - o DP é, pois, marcado com o nominativo.

Enfim, a proposta de R\&U de que a ocorrência de DP[-acus] pós-verbal se explica diante da possibilidade de marcação ou do partitivo, ou do nominativo à distância, a esse DP não explica tal ocorrência nos dados do PB.

\subsection{Das propriedades semânticas do DP[-acus] pós-verbal}

A comparação dos dados do PB aos dados do PE aponta para duas restrições:

Restrição[A]: No PE, diferentemente do que se verifica no PB, o licenciamento de DP[-acus] pós-verbal está relacionado ao Efeito de Definitude - em certos casos, o DP[-acus] só é licenciado se é indefinido. 
Restrição[B]: No PB, diferentemente do que ocorre no PE, o licenciamento de DP[-acus], em certos casos, exige que o DP receba uma leitura contrastiva; ou seja, um acento, do qual resulta um efeito de contraste a um elemento, de certa forma, já mencionado no discurso.

NASCIMENTO (1984) contesta a análise segundo a qual, em português, a leitura contrastiva é a condição necessária à aceitabilidade da ORDEM V-S (cf. PERLMUTTER, 1976), alegando que as sentenças como ( $7 \mathrm{~b}, \mathrm{c})$, repetidas como (24a, b), abaixo - que devem ser analisadas como frases apresentativas com verbos que introduzem contexto de lista - são perfeitamente boas no PB, sem leitura contrastiva. Intuitivamente, parece possível associar a estrutura dessas sentenças à estrutura das sentenças (21a) e (23a), que, como ilustra (25), pode ser parcialmente representada por (26):

(24) a. [ Correu [ um/o carro de que todos falavam ] ]

b. [ Havia na mesa [ uma/a faca de cortar pão ] ]

(25) [ Ficaram [ os/esses/alguns soldados sem armas ] ]

(26) $\left[_{\mathrm{VP}} \mathrm{V}(\mathrm{XP})\left[_{\mathrm{DP}}\left[{ }_{\mathrm{D}}[\mathrm{NP}(\mathrm{XP})]\right]\right]\right]$

A estrutura representada em (26) parece poder ser também a de algumas das frases do PB nas quais, segundo FIGUEIREDO SILVA, o DP [-acus.] pós-verbal pode ocorrer, se seguido de outro sintagma, como em (27):

(27) [ Saiu $\left[_{\mathbf{D P}}\left[\mathbf{D}\right.\right.$ a $\left[_{\mathbf{N P}}\right.$ renovação $\left[_{\mathbf{P P}}\right.$ da minha bolsa $\left.\left.]\right]\right]$

Diante desses dados, a restrição [B], relativa ao $\mathrm{PB}$, pode ser, assim, reformulada:

\section{Restrição [B] reformulada}

No PB, o DP[-acus] pós-verbal é licenciado se tem como referente elemento(s) de um conjunto, destacado(s) por: (i) um acento no referido DP, o que gera o efeito de contraste desse(s) elemento(s) com outro(s) já mencionado(s) no discurso; (ii) restrição 
desse(s) elemento(s) ao ser(em) introduzido(s) no discurso, do que resulta ou a inclusão de quantificadores (não universais) no DP, ou a inclusão do DP em descrições definidas.

Apesar de distintas, a restrição [A], imposta ao licenciamento do DP[-acus] pós-verbal no PE, e a restrição [B], acima, imposta ao licenciamento do DP[-acus] pós-verbal no $\mathrm{PB}$, apresentam um ponto em comum, ou seja: ambas estão relacionadas ao conteúdo referencial (ou propriedades semânticas) do DP.

A relação entre a ocorrência de um DP[-acus] pós-verbal e o conteúdo referencial desse DP é observada por BERLINCK (1994), que, assumindo a "restrição de monoargumentalidade" postulada por TARALLO \& KATO (1989), examina, à luz do modelo laboviano, um corpus constituído de 127 sentenças inacusativas do PB e conclui que a variação ORDEM V-S/ordem SV encontrada nesses dados "não pode ser resolvida no nível da frase", o que implica "buscar motivações no nível da organização do discurso". Ao identificar as relações entre estrutura e função, BERLINCK aponta, como presente nos dados examinados, a possibilidade de sentença com o sujeito gramatical imediatamente depois do verbo, ou depois do predicado, e propõe que: (a) no segundo caso (de "falsa inversão", nos termos de KATO, 1992), o sujeito de Flexão é um pronome nulo referencial cujo antecedente já foi dado anteriormente no discurso, ou é supostamente recuperável e por isso aparece no final da frase; (b) no primeiro caso, a estrutura é utilizada para introduzir, no discurso, um referente novo, ou já dado e reintroduzido, que freqüentemente passa a ser o tópico discursivo. De acordo com a autora, a novidade do referente pode representar um efeito de contraste com algum elemento do texto, o que foi "bastante recorrente entre os dados analisados" e é ilustrado pelo exemplo abaixo transcrito:

(28) ... antigamente o pessoal ia, a gente via casais agora não eu acho que vai mais estudante.

BERLINCK relaciona, então, o efeito de contraste à noção de Novo (em oposição a Dado), que seria relevante para a ocorrência da então chamada ORDEM V-S no PB. 


\section{UMA REINTERPRETAÇÃO DA CHAMADA ORDEM V-S NO PB}

Conforme anteriormente mencionado, as diversas propostas de explicação para o licenciamento do DP[-acus] em posição pós-verbal encontradas na literatura, por um lado, mostram-se todas preocupadas em solucionar a questão do caso desse DP, mas, por outro lado, associam tal licenciamento a restrições que remetem à necessidade de se recolocar a questão em relação ao fenômeno; essa questão, formulada como em (8), será, por conveniência, repetida como (29), abaixo:

(29) Por que, em determinadas sentenças com verbos inacusativos, o DP[-acus], tradicionalmente analisado como sujeito, não se move para a posição de Espec/TP a fim de se envolver na checagem do traço-D de T e ocorre em posição pós-verbal?

Considerando-se os dados, do PB e do PE, examinados na seção anterior, é possível supor que, em determinadas sentenças inacusativas, o DP[-acus], tradicionalmente analisado como sujeito, não se move para o Espec/TP a fim de se envolver na checagem do traço-D de T e ocorre em posição pós-verbal, por razão de natureza semântica. Essa hipótese norteará, portanto, a reinterpretação das sentenças do PB que vêm sendo tratadas como as que ainda exibem ORDEM V-S, que será apresentada nas próximas subseções.

\subsection{Das construções com verbo[-acusativo]}

Segundo CHOMSKY (1995), caso é um traço cuja marcação constitui uma propriedade de determinadas categorias, e a marcação do acusativo é especificada em V(erbo). Assim sendo, é possível distribuir os verbos em dois grupos:

1) verbos especificados positivamente quanto à propriedade Marcador de Caso Acusativo (ou seja: V [+MCAcus] );

2) verbos especificados negativamente quanto à propriedade Marcador de Caso Acusativo (ou seja: V [-MCAcus] ). 
Os verbos [+MCAcus] são aqueles que a literatura registra como atribuidores de, pelo menos, dois papéis- $\theta$ - um atribuído a um argumento interno, que exerce a função de complemento de V; outro atribuído a um argumento externo, que vai exercer a função de sujeito. Assumindo, com FUKUI \& SPEAS (1986), que V é núcleo de uma projeção máxima lexical e, por isso, não inclui posição de Espec $\left(V^{\prime}=\mathrm{VP}\right)$, o argumento externo é gerado em adjunção a VP, como representado a seguir:

(30) a. O João comprou o livro.

b.

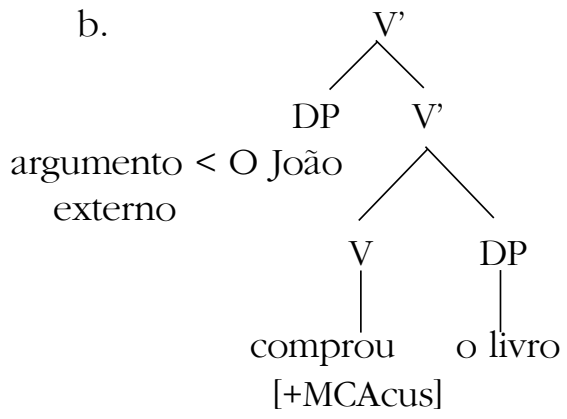

Os verbos [-MCAcus] incluem:

a) verbos que não atribuem papel- $\theta$ e, portanto, se envolvem apenas em construções nas quais não figura argumento; esses verbos incluem: os nocionais como chover e anoitecer, que não se envolvem em relação de complementação; o verbo sere os verbos pseudo-copulativos (estar, ficar, etc.), que vão permitir o licenciamento de mini-orações geradas como seus complementos.

b) verbos que atribuem um único papel- $\theta$ (ex: chegar, correr, trabalhar) e, portanto, se envolvem em construção em que figura um só argumento (V = "monoargumental").

De modo geral, o argumento de V[-MCAcus] tem sido analisado como um argumento interno, ou seja, um argumento representado por um DP[-acus] que, apesar de exercer a função de sujeito, é gerado como irmão de V - do que resulta a ORDEM V-S. Segundo 
R\&U, o PE permite a ocorrência do DP[-acus] (e, portanto, do V[-MCAcus] atribuidor de um papel- $\theta)$ em sentenças como (31a-c) e (32a-c), mas rejeita a ocorrência do DP[-acus] definido em posição pós-verbal não-final, como em (31d) e (32d):

(31) a. Os/Alguns estudantes chegaram tarde.

b. Chegou um estudante tarde.

c. Chegou tarde o estudante.

d. *?Chegou o estudante tarde.

(32) a. O Manel nasceu com uma costela partida.

b. Nasceu um rapaz com uma costela partida.

c. Nasceu com uma costela partida o Manel.

d. *?Nasceu o Manel com uma costela partida.

A análise das sentenças (31a) e (32a) como resultantes de construções em que o DP é gerado como argumento interno a $\mathrm{V}$ e sobe para o Espec/IP poderia, em princípio, ser mantida no atual estágio da Teoria Gerativa, se modificada (e, obviamente, justificada) a motivação para o movimento do DP - que não seria em função do recebimento, mas, sim, da checagem do nominativo. Quanto ao contraste entre as sentenças (b) e (d) contidas em (31) e (32), esse é um fato que tem sido assim explicado: o DP é gerado como um argumento interno (um objeto temático); se é indefinido, permanece in situ, uma vez que recebe o partitivo do V[-acus] e satisfaz o Efeito de Definitude. Essa explicação, no entanto, não pode ser atribuída às sentenças (31c) e (32c), que BELLETTI (1988) analisa assumindo a noção de regência, atualmente descartada no âmbito da Teoria Gerativa. Tais sentenças deixam de constituir mistério diante da proposta de KATO (1992) de que a seqüência V DP contida em sentenças desse tipo no PB é uma "Falsa Inversão", ou seja: o DP é um antitópico (não o sujeito) e o Espec/IP é ocupado por um pronome sujeito (nulo ou lexical) correferencial ao anti-tópico. 
Conforme atestam os dados abaixo, o PB não permite que um pronome objeto (nulo ou lexical) - isto é, um elemento indiscutivelmente gerado como argumento interno a $\mathrm{V}$ - seja correferencial a um anti-tópico:

(33) a. Todos conhecem o Filipe.

b. O Filipe, todos conhecem pro $_{\mathbf{i}}$,

c. ?O Filipe , $_{\mathbf{i}}$ todos conhecem ele.

d. *?Todos conhecem ele ${ }_{i}$ o Filipe ${ }_{i}$.

a. *Todos conhecem pro $_{i}$, o Filipe ${ }_{\mathbf{i}}$

(34) a. Devo levar o Filipe a essa festa.

b. O Filipe ${ }_{\mathbf{i}}$, devo levar pro $_{\mathbf{i}}$, a essa festa.

c. ?O Filipe ${ }_{\mathbf{i}}$, devo levar ele a essa festa.

d. *?Devo levar ele a essa festa, o Filipe ${ }_{\mathbf{i}}$.

e. *Devo levar pro a essa festa, o Filipe . $_{i}$

Diante desse fato, portanto, a hipótese de que um pronome sujeito (lexical ou nulo, correferencial a um antitópico) é gerado como argumento interno a $\mathrm{V}$ (que lhe atribui o papel- $\theta$ ) e é movido para o Espec/IP não se sustentaria. Assim sendo, o pronome sujeito das sentenças tais como (31c) e (32c) - que, segundo KATO, contêm a seqüência V DP constituindo uma "Falsa Inversão" - deve ser analisado como um argumento externo a VP. Enfim, as análises atribuídas às sentenças de (31) e (32) apontam, então, para a possibilidade de o papel- $\theta$ atribuído por um V [-MCAcus] ser associado a um argumento interno a $\mathrm{V}$, ou a um argumento externo a VP. Esse fato vai permitir supor que um Verbo [-MCAcus] atribuidor de papel- $\theta$ pode:

a) não subcategorizar um argumento interno; nesse caso, o V é um predicador, ou seja, uma categoria lexical que se envolve numa relação, semântica, de Predicação e, conseqüentemente, o papel- $\theta$ (é atribuído a um DP gerado como argumento externo a VP: 
(35) a. A carta chegou.

Chegar: V, Tema $<->$

$\mathrm{b}$

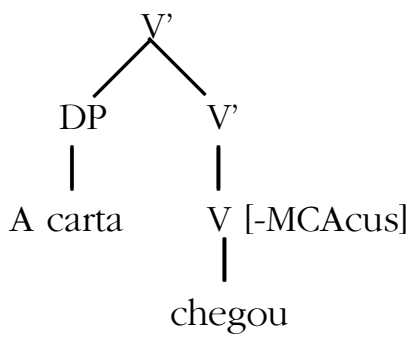

b) subcategorizar um argumento interno; nesse caso, o V não se envolve numa relação, semântica, de Predicação (não é um predicador) mas, sim, numa relação, semântica, de Complementação (assim sendo, o papel- $\theta$ é atribuído a um DP gerado como irmão de V):

(36) a. Chegou a carta. Chegar: $\mathrm{V},<-$ DP $>$ Tema

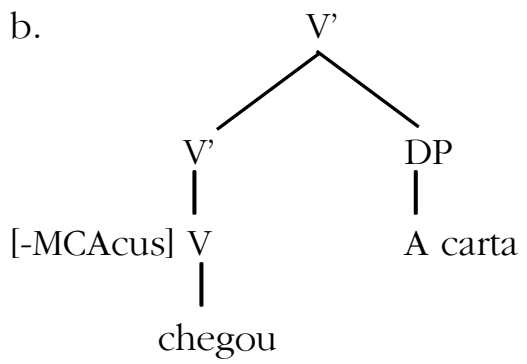

Essa hipótese suscita, pois, a seguinte questão: na construção de uma sentença com um V [-MCAcus], a que se deve a opção por uma das estruturas argumentais desse V?

De acordo com CHOMSKY (1995), o traço marcar caso (um traço especificado em V e em T) é [-interpretável] e, portanto, exige checagem, que pode ocorrer antes ou depois do Spell Out, na medida em que pode se dar através de movimento explícito de um constituinte, ou de movimento implícito de traços. Em decorrência dessa dupla possibilidade de checagem do traço marcar caso, um DP [+Nominativo] pode, portanto, se envolver na checagem do traço 
Marcar Caso Nominativo de T sem se mover para o Espec/TP. Assim sendo, pode-se supor o seguinte: o Sujeito - uma posição sintática obrigatória (cf. CHOMSKY, 1995: o PPE) - definida como a posição de Espec/TP, onde não figura necessariamente um elemento q-marcado, pode não ser ocupada por um DP, mesmo especificado [+Nominativo], que recebe o papel- $\boldsymbol{\theta}$ de um V[-MCAcus], uma vez que esse DP pode se envolver na checagem do traço Marcar Caso Nominativo de T, ou movendo-se para o Espec/TP, ou sem se mover para o Espec/TP (isto é, através do movimento implícito do seu traço [+Nominativo]); em vista disso, o V [-acus] atribuidor de papel- $\theta$ pode se envolver em dois tipos de construção, significativamente diferentes:

1) Construção de sentenças em que o papel- $\theta$ atribuído pelo V é associado a um DP, argumento externo a VP, que sobe para Espec/ $\mathrm{TP}$ - do que resultam as sentenças contendo [DP (x) V (y)], como (62a) e (63a), e contendo [pro V (x) DP], como (62c) e (63c);

2) Construção de sentenças em que o papel- $\theta$ atribuído pelo V é associado a um DP, argumento interno a $\mathrm{V}$, que permanece in situ - do que resultam as sentenças contendo [Expletivo V (x) DP (y)], como (62b) e (63b).

Mas essa hipótese, além de não explicar o contraste entre as sentenças (b) e as sentenças (d), contidas em (31) e (32), ainda deixa sem resposta a questão acima, que pode ser, assim, reformulada: se um V[-acus] pode servir a dois tipos de construção, a que deve ser atribuído o fato de ser incluído ora num tipo, ora noutro?

A motivação para o V[-acus] ser incluído, ora em Construção do Tipo 1, ora em Construção do Tipo 2, no PE, parece poder ser encontrada na explicação do referido contraste como resultante do licenciamento de um DP em posição pós-verbal não-final de sentença que se constrói com V[-acus] se esse DP é indefinido. Em outras palavras, as sentenças derivadas da construção do Tipo 2 seriam marcadas, por incluírem um DP indefinido, especificado [+Partitivo]. Só que essa análise, capaz de explicar inclusive o contraste entre as sentenças de (37), o contraste entre as sentenças 
de (38) e a gramaticalidade de (70a), no PE, não explicaria a gramaticalidade de (70b), atribuída por R\&U a uma estratégia não-pertinente no atual estágio da Teoria: a marcação do nominativo à distância.

(37) a. Em Beirute, ficaram alguns soldados feridos.

b. ?"Ontem em Beirute ficaram os soldados feridos.

(38) a. Continuava um meu amigo doente.

b. "Continuava o meu amigo doente.

(39) a. Em Beirute, ficaram ontem alguns soldados sem armas.

b. Em Beirute, ficaram ontem os soldados sem armas.

Além disso, como visto na seção 2, as sentenças de (37), (38) e (39) são todas permitidas no $\mathrm{PB}$ se recebem leitura contrastiva. O acento contrastivo (ou efeito de contraste) é típico de Foco (cf. NASCIMENTO \& KATO), que, de acordo com ZUBIZARRETTA (1995), é uma noção semântica que tem um correlato fonológico, como explicitado a seguir.

\subsection{Foco: uma noção semântica com um correlato fonológico}

Para ZUBIZARRETTA (1995), as noções de informação Velha e de informação Nova são discursivas - tendo pouca relevância para a gramática - e a definição de foco como informação Nova é problemática, na medida em que informação Velha também pode ser focalizada (ou seja, constitui o foco contrastivo), como atestam os exemplos abaixo:

(40) a. John hit Mary, and then SHE hit HIM.

b. A: - What did John eat: a hamburger or a hotdog?

B: - He ate a HAMBURGER.

A autora assume, então, a seguinte definição de foco em termos das noções pragmáticas de pressuposição e asserção (cf CHOMSKY, 1971; JACKENDOFF, 1972): a pressuposição numa sentença é aquele aspecto da sentença que constitui uma assunção partilhada pelo falante e pelo ouvinte; a parte não-pressuposta (ou foco) da sentença 
constitui a asserção. Para a autora, a distinção entre foco e pressuposição baseia-se na noção "contextualmente-ancorada de verdade presumida". Admitindo uma certa sobreposição das noções de informação Velha/ Nova e as noções de pressuposição/asserção - ou seja, que a informação Nova é parte da asserção (e, portanto, o foco) e a informação Velha pode ser parte de pressuposição ou de asserção ZUBIZARRETTA (1995, p. 27) afirma que "when the asserted constituent constitutes 'old' or discourse-linked information, it gives rise to what is generally know as (explicit) 'contrastive focus'."

Adotando a distinção postulada no SPE (CHOMSKY \& HALLE, 1968) entre padrão prosódico não-marcado-gerado pelo algoritmo núcleo (Nuclear Stress Rule (NSR), que prevê o acento mais à direita da frase) - e o padrão prosódico marcado (que não é gerado pelo NSR e, por consistir na não-coincidência do foco da sentença com a posição do acento principal definido pelo NSR, constitui uma distorção do padrão prosódico não-marcado), ZUBIZARRETTA assume (seguindo CHOMSKY, 1971 e JAKENDOFF, 1972) que:

a) em certas línguas (tais como o inglês, o alemão e o espanhol), a noção semântica de foco tem um correlato fonológico, ou seja, em FF, foco é definido em termos de proeminência prosódica: o constituinte que contém o foco de uma $S$ tem que conter, também, a palavra prosodicamente mais proeminente em $S$;

b) essa exigência (não apresentada por toda língua; em certas línguas africanas, por exemplo, o foco é identificado, em FF, através de um afixo morfológico e, não, através da prosódia) constitui o Focus/ Prosody Correspondence Principle (FPCP), assim formulado, em termos da noção de "conjunto de constituintes-F" de modo a incluir focos não-constituintes:

(41) "The F-set of an IntP ${ }_{i}$ must contain the word that bears main prominence within IntP $_{i} . "$ (onde IntP = intonational unit) (ZUBIZARRETA, 1995, p. 56) 
ZUBIZARRETTA argumenta, então, que "scrambling" no espanhol é motivado por considerações prosódicas e, não, morfológicas (como proposto por CHOMSKY, 1992, 1995); esse tipo de movimento - "Pmovement - aplica-se em FF a fim de permitir que a estrutura satisfaça o FPCP, ou seja, esse movimento cria uma configuração na qual o constituinte focalizado possa receber o acento principal através do algoritmo não-marcado. Assim, o padrão prosódico nãomarcado é gerado pelo algoritmo não-marcado e permite uma leitura de foco largo, enquanto o padrão prosódico marcado envolve "Pmovement" ou desacentuação e está sistematicamente associado a foco "estreito". Essa distinção é ilustrada através de (42):

(42) a. [F Todos los días lee Juan el DIARIO]

b. Todos los días lee el diario [F JUAN]

c. Todos los días lee [F JUAN] el diario.

Em (42a), a proeminência principal recai sobre o objeto e a sentença inteira pode constituir a asserção (isto é, o foco); em (42b), há um padrão prosódico "marcado" e o sujeito é o foco - o 'P-movement' se aplica, gerando a ordem VOS, de modo que o sujeito passa a ocupar uma posição onde recebe o acento via algoritmo não-marcado; em (42c), o padrão prosódico "marcado" é derivado da desacentuação e mudança do acento, um mecanismo utilizado nos casos em que não há alteração na ordem das palavras ou na estrutura sintática.

Ao ressaltar os dois aspectos que determinam se uma elocução é gramaticalmente "neutra" (não-marcada) - as propriedades de FF (a sua forma prosódica) e as propriedades de FL (sua estrutura de pressuposição/foco) - ZUBIZARRETTA (que, doravante, será identificada como ZU, em exemplos aqui transcritos que foram por ela utilizados) distingue: sentença "neutra", se não fragmentada em partes que constituem pressuposição e asserção (possível em contexto isolado); sentença "não-neutra" (isto é, marcada), se é fragmentada em pressuposição e asserção (impossível em contexto isolado), e aponta dois testes que permitem identificar a estrutura foco/pressuposição: 
a) construção de pares "Question/Answer", nos quais as respostas incluem asserção (identificada através de \{ \} em (43), abaixo, transcrito de ZU, 1995, (27)):
(43) a Q: What did John eat?
A: John ate $\{$ PEARS $\}$.
b. Q: What did John do?
A: John \{ate PEARS\}.
c. Q: What happened?
A: $\{$ John ate PEARS $\}$.

b) o uso dos operadores sensíveis a foco - only, even, and negation - associados ao objeto focalizado, ilustrado em (44):

(44) a. John only ate \{pears\}, not apples.

b. John only \{ate pears\}, he did not drink wine.

Assumindo a idéia de que um traço F é que possibilita o par correto FF (prosódia) e FL (divisão da proposição: asserção/ pressuposição), ZUBIZARRETTA (1995, p. 28) propõe que:

...this feature is assigned freely to nodes in the syntactic derivation, the only constraint being that a node marked $\mathrm{F}$ may only dominate nodes marked $\mathrm{F}$ and a node marked $-\mathrm{F}$ may only dominate nodes marked -F. (...) at PF the category marked $\mathrm{F}$ must dominate the word wich main prominence within the intonational phrase...

A autora busca, então, relacionar a possibilidade de várias ordens das palavras no espanhol ao fato de a noção semântica de foco ter um correlato fonológico nessa língua, que inclui, entre outros, os seguintes casos de ORDEM V-S

A) A ordem "VSO onde há um foco não-marcado F", em sentenças que podem ser interpretadas como tendo focalizado apenas o sujeito posposto ou todo o VP, como em (45). Nessas sentenças, possíveis como resposta a pergunta QU- ou em contexto isolado, o objeto é desacentuado por estar em adjunção (provavelmente, a IP), e o sujeito recebe o acento principal da sentença através da regra de acento não-marcado (como o nódulo mais profundamente encaixado). 
(45) La lavó MAMA, la mamadera. (ZU, 1995, (4a), p. 67))

B) A ordem "VOS onde há um foco marcado", em sentenças que podem ser interpretadas como tendo apenas o sujeito posposto focalizado, como em (46). Nessas sentenças, também só possíveis como respostas a perguntas QU- ou em situações contrastivas, o objeto é um sintagma desacentuado por estar em adjunção a VP; a estrutura subjacente é VSO e, por efeito do "P-movement", o objeto é adjungido à projeção máxima imediatamente acima do sintagma marcado F (cf. ZU, 1995, (39)), e o sujeito pós-verbal recebe o acento principal da sentença através da regra de acento não-marcado (como o nódulo mais encaixado da estrutura).

(46) Trajo el vino \{JUAN\}. (ZU, 1995, (37a), p.98 )

C) A ordem "VS (portanto, com verbo não-transitivo) onde há um foco não-marcado", em sentenças às quais não é, necessariamente, atribuída a interpretação de que o sujeito pós-verbal é um foco estreito, como em (47). Nessas sentenças, que podem ocorrer como respostas a perguntas QU- ou em contextos isolados, o sujeito pósverbal recebe, então, o acento principal da sentença através da regra de acento não-marcado (como o nódulo mais encaixado da estrutura).

(47) a. \{Llamó \{JUAN\}] (ZU, 1995, (32c))

b. [Todo el día trabajó \{JUAN\}]. (ZU, 1995, (32d))

\subsection{O Licenciamento do DP [-Acus] Pós-verbal}

\subsubsection{Da Identificação do Foco nas Sentenças Inacusativas}

Seguindo ZUBIZARRETTA (1995), para quem um dos aspectos que determinam se uma elocução é gramaticalmente "neutra" (nãomarcada) são as propriedades de FL (sua estrutura de pressuposição/ asserção ou foco), é possível distribuir as sentenças inacusativas do $\mathrm{PB}$ em dois tipos: 
a) sentenças "neutras" (isto é, não-marcadas e possíveis em contexto isolado), por conterem apenas asserção (da qual o DP é parte), como as de (48), abaixo (nas quais, adotando-se, aqui, a convenção usada por ZUBIZARRETTA, a asserção pode ser identificada através de \{\}$)$ :

(48) a. $\{\mathrm{Um} / \mathrm{O}$ estudante chegou tarde\}.

b. $\{\mathrm{Um} / \mathrm{O}$ estudante foi convidado para a festa\}.

b) sentenças "não-neutras" (isto é, marcadas e impossíveis em contexto isolado), por serem fragmentadas em pressuposição e asserção (sendo o DP a parte assertada), como as de (49):

(49) a. Chegou $\{u m / o$ estudante\} tarde.

b. Foi convidado \{um/o estudante\} para a festa.

c. Chegou tarde \{um/o estudante\}.

d. Foi convidado para a festa $\{\mathrm{um} / \mathrm{o}$ estudante\}.

Tal distinção pode ser evidenciada através dos dois testes similares aos que ZUBIZARRETTA aponta para a identificação da estrutura pressuposição/foco no inglês:

1ํ) A construção de pares "Pergunta/Resposta", nos quais as respostas incluem asserção como em (50):

(50) a P: O que aconteceu?

b. P: Quem chegou tarde?

c. P: Chegou tarde quem?
R: \{um/o estudante chegou tarde\}

R: \{um/o estudante\} chegou tarde.

R:Chegou tarde \{um/o estudante\}.

$2^{\text {o) }}$ O uso dos operadores sensíveis a foco - apenas, só, somente - associados ao elemento focalizado, ilustrado em (51):

(51) a. Chegou apenas/só \{UM/O ESTUDANTE\} tarde; não o professor.

b. Chegou tarde apenas/só \{UM/O ESTUDANTE\}; não o professor.

c. Foi convidado apenas/só \{UM/O ESTUDANTE\} para a festa; não o professor.

a. Foi convidado para a festa apenas/só \{UM/O ESTUDANTE\}; não o professor. 
Além disso, cabe ressaltar que as sentenças de (49) são permitidas como formas de contestação/retificação a afirmações feitas em relação a um conjunto de referentes, dentre os quais se destaca o referente expresso pelo DP pós-verbal, que recebe o acento contrastivo como mostram os dados abaixo:

(52) A: - Não houve aula porque os estudantes chegaram tarde.

B: - Chegou UM/O ESTUDANTE tarde.

- Chegou tarde UM/O ESTUDANTE.

(53) A: - Amanhã não haverá aula porque todos foram convidados para a festa.

B: - Foi convidado UM/O ESTUDANTE para a festa.

- Foi convidado para a festa UM/O ESTUDANTE.

O mesmo se verifica nas sentenças de $\mathrm{B}$, a seguir:

(54) A: - Em Beirute, TODOS/OS SOLDADOS ficaram feridos/sem armas.

B: - Em Beirute, ficaram ALGUNS/ESSES SOLDADOS feridos/sem armas - Em Beirute, ficaram ELES feridos/ sem armas.

(55) A: - Em Beirute, TODOS/MUITOS/OS GENERAIS ficaram feridos/ sem armas.

B: - Ficaram ALGUNS/ESSES/OS SOLDADOS feridos/sem armas.

- Ficaram ELES feridos/sem armas.

Assumindo, com ZUBIZARRETTA, que, em certas línguas, o constituinte que contém o foco de uma S(entença) contém, também, a palavra prosodicamente mais proeminente de S (FPCP) e que, se tais línguas apresentam o padrão prosódico "não-marcado" gerado pela NSR - que prevê o acento mais à direita da frase - a nãocoincidência do foco da sentença com a posição do acento principal definido pela NSR resulta num padrão prosódico "marcado", é possível, diante desses dados e dos examinados na seção 3, supor que, no PB: 
(a) assim como, segundo a referida autora, ocorre no espanhol, no francês e no inglês, o foco é definido, em FF, em termos de proeminência prosódica;

(b) o padrão prosódico "não-marcado" é gerado pela NSR, que prevê o acento mais à direita da frase, de modo que a não-coincidência do foco da sentença com a posição do acento principal definido pela NSR resulta num padrão prosódico "marcado";

(c) o DP pós-verbal das sentenças inacusativas do PB é um constituinte (ou parte de um constituinte) foco, que recebe $\mathrm{O}$ acento mais proeminente de $\mathrm{S}$, podendo figurar, tanto numa posição coincidente com a posição do acento principal da sentença gerado pela NSR, do que resulta um padrão prosódico "não-marcado" (o que se verifica em (56a,b), abaixo), quanto numa posição não-coincidente com a posição do acento principal da sentença gerado pela NSR, do que resulta um padrão prosódico "marcado", como ocorre em (56c):

(56) a. Chegou $\{[D P$ UM/O ESTUDANTE $]$.

b. Chegou $\{[D P$ A CONTA DE TELEFONE $]\}$

c. Chegou $\{[$ DP UM/O ESTUDANTE $]\}$ tarde.

Se essa hipótese é correta, parece evidente que as sentenças de (49) resultam de operações diferentes das envolvidas na construção das sentenças de (48).

\subsubsection{O DP [-Acus] Pós-verbal: um Objeto Nominativo}

Tendo-se em vista as noções de construção, "checagem de traços" e "tipos de traços" encontradas em CHOMSKY(1995), assumese, no presente estudo, que:

1) Caso e traços- $\phi$ são adicionados arbitrariamente quando um nome é selecionado para a numeração (CHOMSKY, 1995, seção 4.1, p.28).

2) O Movimento de um DP para se envolver numa operação de checagem de Caso é , então, motivada pelo traço marcar caso - 
um traço intrínseco de $\mathrm{V}$ ou de $\mathrm{T}$ e, não, do DP - que é [-interpretável] e deve, portanto, ser checado, mas essa checagem pode ocorrer antes ou depois do Spell Out, já que pode ser através de movimento explícito de um constituinte, ou de movimento implícito de traços.

3) Diferentemente do que propõe ZUBIZARRETTA, o traço F que possibilita o par correto FF (prosódia) e FL (divisão da proposição em asserção e pressupo-sição) não é marcado livremente a nódulos na derivação sintática, mas constitui um traço abstrato, opcional e [+interpretável], especificado na entrada lexical.

4) Na derivação sintática, o nódulo que domina a categoria especificada [+F] é também marcado [+F] e, nas línguas em que foco tem um correlato fonológico, esse nódulo tem que dominar a palavra, do ponto de vista prosódico, a mais proeminente da sentença.

A partir desses pressupostos, é possível supor que as sentenças do PB que vêm sendo tratadas na literatura como casos de ORDEM V-S - e que, cabe ressaltar, contêm apenas verbo [-MCAcus] - são construídas com base numa Numeração que contém verbo [-MCAcus] e inclui um elemento especificado com o traço $[+F]$, do que resulta uma estrutura completamente diferente da estrutura resultante de operações realizadas com base numa Numeração que também contém verbo [-MCAcus], mas "não inclui" elemento especificado com o traço $[+\mathrm{F}]$.

Assim sendo, as sentenças que apresentam o primeiro tipo de estrutura acima mencionado podem ser analisadas como resultantes da seguinte derivação:

Uma entrada lexical $\mathrm{N}$ marcada com o traço $[+\mathrm{F}]$ projeta um N' (NP, nos termos de FUKUI, 1986) que vai ser o complemento de um D, núcleo de um DP, que carrega o papel- $\theta$ (Tema) selecionado pelo V. Esse DP (não especificado [+Acusativo]) que contém, portanto, um elemento especificado com o traço $[+\mathrm{F}]$ e deverá receber o acento principal da sentença em FF, é gerado na posição de argumento interno a V e permanece in situ. Pelo fato de esse DP não poder subir 
para se envolver na checagem do traço-D de T, um expletivo é inserido na derivação. A presença desse expletivo - que, embora não tendo conteúdo fonético, é uma categoria, como there do inglês, especificada [+traço-D, -Traço- $\phi$, -papel- $\theta$, -Caso] - não permite, então, a checagem do traço Marcar Caso Nominativo de T; tal checagem vai envolver o movimento implícito do traço Caso do DP[-acus], que se adjunge a $\mathrm{T}$.

À estrutura que resulta dessas operações, associam-se sentenças como as de (48) e a de (9a), que como será mostrado mais adiante, são diferentes de sentenças como as de (56) e a de (9b), que podem ser associadas ao segundo tipo de estrutura anteriormente mencionado, ou seja, analisadas como resultantes da seguinte derivação:

Uma entrada lexical $N$ não-marcada com o traço $[+F]$ projeta um N' (NP, nos termos de FUKUI, 1986) que vai ser o complemento de um D, núcleo de um DP, que carrega o papel-? (Tema) selecionado pelo V. Esse DP (não especificado [+Acusativo]), que não contém elemento especificado com o traço [+F] e não precisará, portanto, ocupar uma posição na qual, necessariamente, incida sobre ele o acento principal da sentença em FF, é gerado na posição de argumento externo a V. Esse DP pode, então, subir para se envolver na checagem do traço-D de T e, como isso ocorre, o traço Caso desse DP vai permitir também a checagem, na sintaxe visível, do traço Marcar Caso Nominativo especificado em T.

Das operações que derivam o segundo tipo de estrutura resultam, então, sentenças "Predicativas", como (9a) - repetida como (57a), abaixo - enquanto, das operações que derivam o primeiro tipo de estrutura, resultam sentenças "Apresentativas", tais como (9b) repetida como $(57 \mathrm{~b})$ :

(57) a. A carta chegou.

b. Chegou a carta.

A estrutura de (57a) e a estrutura de (57b) podem, então, ser representadas, respectivamente, através de (57a') e (57b'), a seguir: 
(57) a'. Construção de Sentença Predicativa

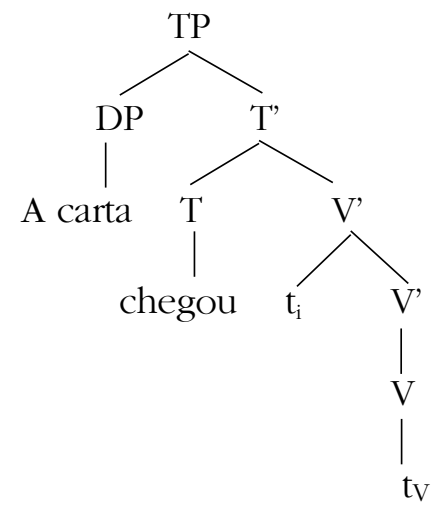

b'. Construção de Sentença Apresentativa

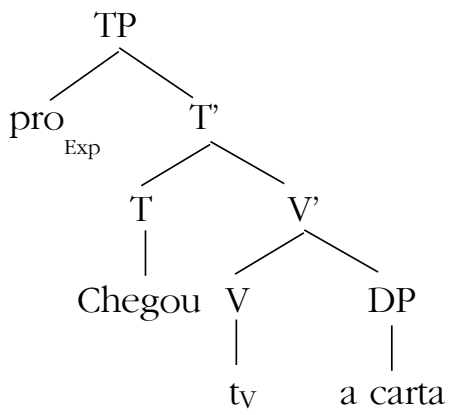

Na sentença (57a), o DP que carrega o papel-? atribuído pelo V [-MCAcus] é gerado como argumento externo a VP e envolve- se na checagem do traço-D de T, de modo que sobe para Espec/TP esse DP é, portanto, o SUJEITO. Essa sentença, Predicativa, apresenta um padrão prosódico não-marcado, podendo ser produzida como resposta à pergunta: O QUE ACONTECEU?, ou em contexto isolado - em ambos os casos, a sentença inteira é asserção e, portanto, o foco.

$\mathrm{Na}$ sentença (57b), o DP que carrega o papel-? atribuído pelo $\mathrm{V}$ [-MCAcus] é gerado como argumento interno a $\mathrm{V}$ e permanece in situ, de modo que não se envolve na checagem do traço-D de T, ou seja, não é SUJEITO e, sim, um Objeto. Essa sentença, Apresentativa, também apresenta um padrão prosódico não-marcado, mas apenas o objeto (isto é, o DP pós-verbal) é a asserção e, portanto, o foco.

Essa distinção pode ser representada através de (58):

a. $\{$ [ F [A carta CHEGOU] $\}$

b. [Chegou $\{$ F A CARTA $\}]$

As sentenças inacusativas do PB contidas em (49a-b) e repetidas como (59), abaixo, podem ser analisadas como sentenças "Apresentativas" com padrão prosódico "marcado" (já que o DP foco ocupa uma posição não-coincidente com a posição do acento principal da sentença 
gerado pela NSR), de modo que a identificação do referido DP (especificado [+Nominativo]) como o foco, na FF, resulta da incidência do acento sobre ele através da Desacentuação e mudança do acento, que torna desacentuado o constituinte mais à direita de $\mathrm{S}$ :

(59) a. Chegou \{UM ESTUDANTE\} tarde.

b. Chegou \{O ESTUDANTE $\}$ tarde.

c. Foi convidado \{UM ESTUDANTE $\}$ para a festa.

d. Foi convidado \{O ESTUDANTE $\}$ para a festa.

Essa mesma análise pode ser atribuída às sentenças de (60), a seguir, nas quais o DP pós-verbal é o sujeito de uma mini-oração PP em (60a) e AP em (60b) - gerada como o argumento interno de $\mathrm{V}$, e esse DP, [+Nominativo], é identificado como o foco, na FF, em decorrência da Desacentuação e mudança do acento; o PP (predicado da mini-oração), que é constituinte mais à direita de S(entença), se torna desacentuado e o DP recebe o acento mais proeminente de $S$ :

(60) a. Ontem em Beirute ficaram \{ALGUNS SOLDADOS\} sem armas.

b. Ontem em Beirute ficaram \{OS SOLDADOS\} sem armas.

c. Em Beirute, ficaram ontem \{ALGUNS SOLDADOS\} feridos.

b. Em Beirute, ficaram ontem \{OS SOLDADOS\} feridos.

As sentenças inacusativas do PB contidas em (49c-d) e repetidas como (61), abaixo, podem ser analisadas como sentenças "Apresentativas" com padrão prosódico "marcado". Nessas sentenças, o DP pós-verbal é o constituinte foco, identificado, em FF, por receber o acento principal de $S$ na posição do acento gerado pela NSR (ou seja, através do algoritmo não-marcado), em conseqüência de uma operação de "P-movement" (o elemento gerado na posição final de $S$ vai ser adjungido ao VP):

(61) a. Chegou tarde \{UM ESTUDANTE\}.

b. Chegou tarde \{O ESTUDANTE\}.

c. Foi convidado para a festa \{UM ESTUDANTE\}.

d. Foi convidado para a festa \{O ESTUDANTE\}. 
A ocorrência do DP [-acus.] definido na posição final da sentença é analisada por KATO (1993) como uma "falsa inversão", na qual, esse DP é um antitópico - não, o sujeito - e a posição de Espec/IP é ocupada por um pronome sujeito (nulo ou lexical) correferencial ao DP pós-verbal (o antitópico). Nos termos da presente análise, as sentenças que exibem essa "falsa inversão" diferem das sentenças de (61), uma vez que podem ser explicadas como a seguir. O papel- $\theta$ do V[-MCAcus.] é atribuído a um pro (argumento externo de VP), que vai ocupar a posição de Espec/TP (onde pode figurar um pronome lexical); um DP que não recebe, portanto, o papel- $\theta$ do $V$ é gerado como um anti-tópico, ao qual pro está coindexado. Nesse tipo de sentença, que apresenta um padrão prosódico não-marcado, o acento principal recai sobre o constituinte adjungido ao VP, como ilustram as sentenças de (62), que são, portanto, Predicativas e diferentes das sentenças de (61) também prosodicamente, como sinalizado abaixo:

(62) a. \{F Chegou TARDE\}, o estudante.

a'. \{Ele chegou TARDE\}, o estudante.

b. \{Foi convidado para a FESTA\}, o estudante.

b. \{Ele foi convidado para a FESTA\}, o estudante.

Esse tipo de sentença é também encontrado no PE, que, conforme mostrou a comparação de dados realizada na seção 2 , difere do PB quanto à construção de sentenças apresentativas. A análise acima proposta para as sentenças apresentativas do PB aponta para a possibilidade de se explicar tal diferença, na medida em que os dados comparados permitem supor, de início, que, nas sentenças do PE, o constituinte foco (ou focalizado), definido semanticamente como a parte não-pressuposta de $S$ (que constitui a asserção), não é identificado através do mesmo mecanismo que o identifica nas sentenças do PB; ou seja, no PE, o DP foco é identificado, em FF, através da indefinitude, do que resulta a seguinte distinção: 
(63)

PB: $\quad \neq$

PE:

a. Chegou UM ESTUDANTE tarde.

c. Chegou um estudante tarde.

b. Chegou O ESTUDANTE tarde.

d. *Chegou o estudante tarde.

Evidentemente, essa hipótese, por si só, não explica o fato de em determinadas sentenças do PE o DP[-acus.] permanecer em posição pós-verbal, nem a possibilidade de, em alguns desses casos, esse DP ser definido. Mas, com base nessa hipótese, o contraste entre as sentenças do PE contidas em (62) pode ser, assim, explicado: a sentença (62c) é construída a partir de uma Numeração que inclui um $\mathrm{N}$ especificado [+F] que é especificado [+Partitivo] e, em decorrência do Efeito de Definitude, o DP que contém esse N é, obrigatoriamente, indefinido; esse DP, que recebe o papel- $\boldsymbol{\theta}$ do V [-MCAcus.], é gerado como argumento interno a $\mathrm{V}$ e identificado, pela indefinitude, como o foco (a parte assertada) da sentença; na medida em que é especificado [+Partitivo], esse DP não pode se envolver na checagem do traço [+ Marcador de Nominativo] de T, o que impede o seu movimento para o Espec/TP; conseqüentemente, essa posição vai ser ocupada por um expletivo, que é inserido na derivação por exigência do traço do traço D (e vai permitir a checagem do traço [+Marcador de Nominativo]) de T; a sentença (62d) é agramatical pelo fato de o Efeito de Definitude estar sendo violado (o DP é especificado [+Partitivo] e, por isso, deveria ser indefinido).

Segundo R\&U (1990), a evidência de que o DP[-acus.] indefinido pós-verbal de sentenças como (93c) é "marcado" com o Caso Partitivo pode ser encontrada no fato de, no galego, tais sentenças admitirem o expletivo lexical no Espec/TP, conforme atesta (64):

(64) a. El chegou un estudiante tarde.

b. El foi convidado un estudiante prá festa.

A indefinitude vai também identificar o DP[-acus.] pós-verbal como o foco em (65a), abaixo. Nessa sentença, construída a partir de uma Numeração que inclui um $\mathrm{N}$ especificado [+F] que é especificado [+Partitivo] e o DP que contém esse N (em decorrência 
do Efeito de Definitude, obrigatoriamente indefinido) se junta a um AP para formar uma mini-oração AP (é o sujeito de AP), gerada como argumento interno a $\mathrm{V}$; à semelhança do observado em relação a (62c, d), o DP, por ser especificado [+Partitivo], é impedido de se mover para o Espec/TP em (65a), que contrasta com (65b) pelo fato de, nessa última, o EFEITO DE DEFINITUDE estar sendo violado (o DP é especificado [+Partitivo] e, por isso, deveria ser indefinido).

(65) a. Em Beirute, ficaram ontem alguns soldados feridos.

b. "Em Beirute, ficaram ontem os soldados feridos. (R\&U, 1990)

No entanto, diante dessa análise, o contraste de (66), a seguir, parece constituir um mistério, uma vez que (66b), com o DP indefinido pós-verbal, é que apresenta problema:

(66) a. Ontem em Beirute ficaram os soldados sem armas.

b. ?Ontem em Beirute ficaram alguns soldados sem armas.

A sentença (66a) aponta para uma destas duas direções: ou o DP dessa sentença não é especificado $[+F]$, ou a indefinitude não é o único recurso que identifica um DP como o foco, em FF, no PE. A segunda opção mostra-se a mais plausível, se levado em conta que o contrate entre os dados do galego contidos em (67) constitui, segundo R\&U (1990), evidência de que o DP[-acus.] definido pósverbal da sentença (97a) é "marcado" Nominativo, razão pela qual, essa sentença não admite o expletivo lexical no Espec/TP:

(67) a. En Beirut, [e] ficaron onte os soldados sen armas.

b. *En Beirut, el ficaron onte os soldados sen armas.

Se o DP pós-verbal da sentença (66a) é especificado [+Nominativo], o DP que figura em (66b), embora indefinido, também o é; tal fato permite concluir que: (i) se a sentença (66b) não é perfeitamente boa, isso não se deve à falta de identificação do DP como o constituinte [+F], pois esse DP é indefinido; (ii) o problema de (66b) provavelmente explica-se pela permanência, desmotivada, do DP [+Nominativo] indefinido na posição pós-verbal; (iii) se a falta de motivação para 
o DP [+Nominativo] indefinido permanecer na posição pós-verbal é que explica (66b), parece claro que, em (66a), a permanência do DP [+Nominativo] definido na posição pós-verbal, é motivada. Podese, então, supor que no PE:

a) o foco não é identificado, em FF, somente através da indefinitude, ou seja, o DP indefinido é sempre um elemento focalizado - ou o foco marcado (especificado $[+\mathrm{F}]$ ), ou parte de um constituinte foco, não-marcado - mas o DP definido, se é especificado [+F], precisa ser identificado como o foco da sentença, em FF, através de um outro recurso, que é a incidência do acento mais proeminente da sentença;

b) o padrão prosódico "não-marcado" também é gerado pela NSR, que prevê o acento mais à direita da sentença, de modo que, se o foco precisa ser identificado, em FF, em termos de proeminência prosódica, a não-coincidência do foco com a posição do acento principal definido pela NSR resulta num padrão prosódico "marcado";

c) o constituinte $[+\mathrm{F}]$ recebe o acento principal de $\mathrm{S}$ nas sentenças com padrão prosódico "marcado", em conseqüência de uma operação de Desacentuação - que não altera a ordem das palavras ou a estrutura sintática - sse é um DP definido (e, portanto, não especificado [+Partitivo]), gerado numa posição interna a V que não é a mais encaixada de $S$.

Com base nessa hipótese, é possível explicar as sentenças de (66), repetidas como (68), abaixo, nas quais, o DP especificado [+F] - que é [+Nominativo], de modo que não é sujeito ao EFEITO DE DEFINITUDE (e pode, portanto, ser definido) - recebe o papel-?, indiretamente, de PP, ao qual se junta para formar uma mini-oração PP (é o sujeito de PP), gerada como argumento interno a V [-acus]:

(68) a. Ontem em Beirute ficaram os soldados sem armas.

b. ?Ontem em Beirute ficaram alguns soldados sem armas.

Em (68b), o DP é indefinido, e a indefinitude pode identificálo como o foco da sentença. Mas, em (68a), o DP é definido e, por isso, precisa ser identificado em FF. Essa sentença apresenta, 
portanto, um padrão prosódico "marcado"; a identificação do DP foco, em FF, é possível, dada a disponibilidade de mecanismo que permite a mudança do acento principal da sentença de modo a incidir sobre esse DP, mas tal mecanismo vai exigir que esse DP permaneça in situ, ou seja: o DP [+F], especificado [+Nominativo] e definido, que é o sujeito da mini-oração complemento, recebe o acento mais proeminente de $\mathrm{S}$ em conseqüência da desacentuação do PP predicado dessa mini-oração e, em vista disso, o referido DP é impedido de se mover para o Espec/TP a fim de checar o traço D de T; conseqüentemente, o seu traço [+Nominativo] vai checar o traço [+ Marcador de Nominativo] de T, através de movimento implícito e a posição de Espec/TP vai ser ocupada por um expletivo [-Caso], que é inserido na derivação em função da checagem do traço D. Na medida em que, em (68b), o DP não precisa ser identificado como o constituinte foco, em FF, não existe impedimento para o movimento desse DP para o Espec/TP a fim de checar o traço D de T; enfim, não há motivação para a permanência desse DP em posição pós-verbal - por isso, tal sentença deixa de ser perfeitamente boa.

\section{CONCLUSÃO}

Essa análise permite responder à questão de (10), repetida como (29), na medida em permite dizer que, em determinadas sentenças inacusativas, o DP[-acus], tradicionalmente analisado como sujeito, não se move para o Espec/TP a fim de se envolver na checagem do traço-D de T e ocorre em posição pós-verbal porque tais sentenças são construídas a partir de uma Numeração que inclui um $\mathrm{N}$ especificado [+Nominativo] e, também, [+F]; o DP que inclui esse $\mathrm{N}$ - também marcado $[+\mathrm{F}]$ - e carrega o papel-? atribuído pelo $\mathrm{V}$ [-MCAcus] é gerado como argumento interno a $\mathrm{V}$ e permanece in situ, de modo a ser identificado como o foco (ou parte do constituinte foco) da sentença.

As sentenças inacusativas de (62), encontradas tanto no PB quanto no PE, podem ser analisadas como sentenças apresentativas, 
nas quais, o DP pós-verbal é um anti-tópico e, não, o sujeito, de modo que não constituem casos de ORDEM V-S.

No PE, se o DP foco especificado [+F] é indefinido, é identificado em FF porque o DP indefinido é sempre um elemento focalizado ou o foco marcado (especificado $[+\mathrm{F}]$ ), ou parte de um constituinte foco, não-marcado; entretanto, a indefinitude não é o único recurso utilizado para a identificação do foco em FF, ou seja, se o DP foco especificado $[+F]$ é definido, é identificado pela incidência do acento mais proeminente da sentença - o que pode implicar a Desacentuação, um mecanismo que permite se deslocar o acento sem que a estrutura sintática e a ordem das palavras sejam alteradas.

No $\mathrm{PB}$, o foco é definido, em FF, em termos de proeminência prosódica; o foco especificado $[+\mathrm{F}]$ pode figurar tanto em sentenças que apresentam um padrão prosódico "não-marcado" quanto em sentenças com padrão prosódico "marcado" e, nesse segundo caso, recebe o acento principal da sentença através do "P-movement" ou da Desacentuação (que implica a mudança do acento, sem alterar a estrutura sintática ou a ordem das palavras).

Nas sentenças com o DP[-acus] pós-verbal com padrão prosódico "não-marcado", esse DP constitui (ou integra um DP "complexo" que constitui) a asserção e, portanto, o foco, de modo que é um constituinte (ou parte de um constituinte) especificado com o traço [+F], que recebe o acento principal da sentença através da regra de acento não-marcado (como o nódulo mais encaixado da estrutura) o que se verifica nas respostas de (69), nos exemplos (7a, b), encontrados em NASCIMENTO (1984) e repetidos como (70a, b), e também no exemplo (27), de FIGUEIREDO SILVA (1994), repetido como (70c):

(69) a. - Alguém (me) telefonou?

- Telefonou UM CLIENTE.

b. - Os assessores foram exonerados.

- Foi exonerado UM ASSESSOR.

c. - Tem alguma coisa prá mim, Seu Geraldo?

- Chegou ESTA REVISTA. 
d. - Nenhum dos meus amigos veio.

- Veio O MILTON.

(70) a. Viajaram $\{[$ DP VÁRIAS MOÇAS $]\}$.

b. Correu $\left\{_{\text {[DP }}\right.$ UM/O CARRO DE QUE TODOS FALAVAM]\}.

c. Saiu $\left\{\left[_{D P}\right.\right.$ A RENOVAÇÃO DA MINHA BOLSA $]$.

Nas sentenças inacusativas com o DP[-acus] pós-verbal que apresentam um padrão prosódico "marcado" (em que o acento principal de S não incide sobre o constituinte mais encaixado da estrutura conforme previsto pela regra NSR), se esse DP - que é um constituinte (ou parte de um constituinte) especificado com o traço [+F] - é gerado numa posição interna a $\mathrm{V}$ que não é a mais encaixada de $S$, o acento principal de $S$ vai ser atribuído ao referido DP em conseqüência de:

A) Desacentuação, o que se verifica em (71):

(71) a. $\left[_{\mathrm{TP}} \operatorname{pro}_{\mathrm{E} 1}\right.$ Ficaram [ ${ }_{\mathrm{AP}}$ OS SOLDADOS [ ${ }_{\mathrm{AP}}$ feridos]]]

b. $\left[_{\mathrm{TP}} \operatorname{pro}_{\mathrm{E} 1}\right.$ Ficaram $\left[_{\mathrm{PP}}\right.$ OS SOLDADOS [ $\left[_{\mathrm{PP}}\right.$ sem armas]]]

B) "P-movement", o que se verifica em (63a) repetida, abaixo, como (72a) e provavelmente explica, também, as sentenças como (7c), repetida como (72b), encontrada em NASCIMENTO:

(72) a. Chegou tarde \{UM ESTUDANTE\}.

b. Havia na mesa \{A FACA DE CORTAR PÃO\}.

Enfim, as sentenças inacusativas do PB que têm sido analisadas como aquelas nas quais ainda ocorrem casos de ORDEM V-S são, como explicitado através de (73b), que é a representação da estrutura de (9b), então repetida como (73a), sentenças Apresentativas, que "não" contêm sujeito posposto/invertido e, sim, um OBJETO NOMINATIVO - isso significa, portanto, que, no PB, não existe a ORDEM V-S. 
(73) a. Chegou A CARTA.

b. TP<smiles>[3H]C[18OH]</smiles>

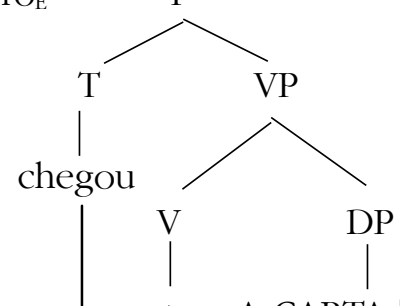

$\mathrm{t}_{\mathrm{V}} \quad$ A CARTA [+F, +NOMINATIVO, $\alpha$ №, $ß$ pessoa $]$

$$
\left[\begin{array}{l}
+\mathrm{N},-\mathrm{V} \\
-\mathrm{pl} \\
-\mathrm{pes} \\
+\mathrm{Nom} \\
+\mathrm{F}
\end{array}\right]
$$

[+NOM, a №, ß pés]

\section{NOTAS}

${ }^{1}$ Este trabalho é uma versão revisada e ampliada da análise proposta no capítulo 4 da minha Tese de Doutorado (ver Referências).

${ }^{2}$ Verbo ergativo é definido por CHOMSKY (1981, p. 282, nota 35) como aquele que não marca Caso, mas atribui papel- $\theta$ (pressupostamente, Tema), ao seu objeto direto (cf. BURZIO, 1981) e não atribui papel- $\theta$ à posição de sujeito.

${ }^{3} \mathrm{Na}$ medida em que não analisa o DP pós-verbal de sentenças inacusativas como sujeito, a proposta de NASCIMENTO \& KATO (1995) permite inferir que esses autores também apontam para o fato de que a Ordem VS não é mais exibida pelo PB.

${ }^{4}$ De acordo com essa análise de KATO, as referidas sentenças, embora contenham a seqüência V DP, não constituem, portanto, casos de ORDEM V-S e, sim de S-V-DP anti-tópico. 
${ }^{5}$ Para a Profa. Mary Kato (c.p.), são exemplos de construções, bem formadas, de antitópico com objeto:

(i) "Todos trouxeram _ pra casa, o bolo."

(ii) "Vou convidar _ pra festa, o Filipe e as meninas."

Na minha opinião, a sentença de (i) não é bem formada - só é possível uma construção como Todos trouxeram pra casa o bolo (e, não, a cerveja), ou seja, uma construção em que o bolo é um Foco; o exemplo (ii) é análogo às construções (33d) e (34d), que são aceitáveis se contêm um elemento lexical na posição de objeto e esse elemento é correferencial a um DP já mencionado, como ilustrado abaixo:

P: - Os meninos vão ser convidados para a festa?

R: - Vou convidar todos pra festa, o Filipe e as meninas.

${ }^{6}$ Segundo Zubizarreta, conforme JACKENDOFF (1972), ROOT (1985) e TANDREDI (1990).

${ }^{7}$ De acordo com Zubizarreta, essa é uma idéia geralmente defendida na literatura (JACKENDOFF, 1972, ROCHEMONT \& CULICOVER, 1990, etc.).

${ }^{8}$ A autora assume que "main prominence is identified as bearing the highest number of asteriks in the metrical grid (as in the theory od stress developed by LIBERMAN \& PRINCE, 1977, SELKIRK, 1984, HALLE \& VERGNAUD, 1987)" - como se verifica na palavra Judea, na sentença a seguir (cf. ZU, 1995, (13)):

(i)

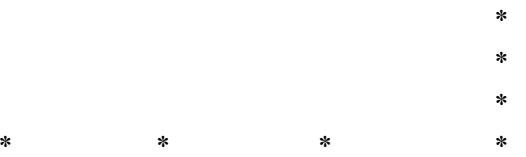

[IP [NP [Jesus]] [VP [preached [to the people [of Judea]]]].

${ }^{9}$ A existência de expletivo (lexical ou nulo) é polêmica e, por limite de espaço, não será aqui discutida. 


\section{REFERÊNCIAS BIBLIOGRÁFICAS}

ÂMBAR, M. Para uma sintaxe da inversão sujeito verbo em português. 1998. Dissertação (Doutorado) - Universidade de Lisboa.

BELLETTI, A. The case of unaccusatives. Linguistic Inquiry, 19:1. p.1-34, 1988.

BERLINCK, R. A inversão verbo-sujeito no português culto falado no Brasil. Campinas: UNICAMP, 1994. (Trabalho inédito).

BITTEnCOURT, V. A posposição do sujeito em português. 1979. Dissertação (Mestrado) - UFMG, Belo Horizonte.

BRANIGAN, P. Subjects and complementizers. Doctoral dissertation, MIT, 1992.

CHOMSKY, Noam. Deep structure, surface structure and semantic interpretation. In: STEINBERG, D.; JAKOBOVITS, L. (Ed.). Semantics: an interdisciplinary reader in Philosophy, Linguistics and Psychology. Cambridge: Cambridge University Press, 1971.

CHOMSKY, N. Lectures on government and binding. Dordrecht: Foris, 1981.

CHOMSKY, N. Knowledge of language: its nature, origin and use. New York: Praeger, 1986.

CHOMSKY, Noam A minimalist program for linguistic theory. In: HALE, K.; KEYSER, S. J. (Ed.) The View from Building 20: Essays in Linguistics in Honor of Sylvain Bromberger. Cambridge, Mass.: The MIT Press, 1993. 1-52.

CHOMSKY, N. The Minimalist Program. Cambridge: MIT Press, 1995.

CHOMSKY, N.; HALLE, M. The sound pattern of English. New York: Harper and Row, 1968.

FIGUEIREDO SILVA, M.C. La position sujet en Portugais Brésilien-dans les phrases finies et infinitives. 1994. Tese (Doutorado) - Université de Genève.

FUKUI, N. A theory of category projection and its applications. 1986. Tese (Doutorado) - MIT.

FUKUI, N.; SPEAS, M. Specifiers and projection. MIT Working Papers in Linguistics, 8, p. 128-172, 1986.

JACKENDOFF, R. S. Semantic interpretation in Generative Grammar. Cambridge: The MIT Press, Mass, 1972.

KATO, M. A. Variação sintática e estilo. Cadernos de Estudos Lingüísticos, 22, Campinas, UNICAMP, p. 127-137, 1992. 
KATO, M. A. Word order change: the case of Brazilian Portuguese Wh-Question. UNICAMP. Paper presented at the 11th International Congress of Historical Linguistics, UCLA, 1993.

KAYNE, R. e J.-Y POLLOCK, Stylistic inversion, successive cyclicity, and Move NP in French. Linguistic Inquiry, 9, 4, 1978.

LIRA, S. Nominal, pronominal and zero subject in Portuguese. 1982. Tese (Doutorado) - University of Pennsylvania.

LIRA, S. Subject postposition in Portuguese. D.E.L.T.A., 2, 1. p. 17-36, 1986.

NASCIMENTO, M. Sur la postposition du sujet dans le Portugais du Brésil. 1984. Tese (Doutorado) - Universidade de Paris VIII.

NASCIMENTO, M.; KATO, M. O estatuto dos nominais pós-verbais dos verbos inacusativos. Revista de Estudos da Linguagem, 4:1, UFMG: Belo Horizonte, p. 1-74, 1995.

NICOLAU, Eunice. As propriedades de sujeito nulo e ORDEM V-S no português brasileiro. 1995. Tese (Doutorado) - UNICAMP.

PERLMUTTER, David M. Evidence for subject downgrading in Portuguese. In: SCHMIDT-RADEFELDT, J. (Ed.). Readings in Portuguese Linguistics. North-Holland Publishing Company, 1976.

RAPOSO, E.; URIAGEREKA , J. Long distance case assignment. Linguistic Inquiry, 21:4. p. 505-537, 1990.

SHLONSKY, U. Null and displaced subjects. 1987. Thèse (Doctorat) - MIT, 1987.

SHLONSKY, U. Rich Infl and Licensing of pro. In: CARDINALETTI, A, G. CINQUE; G. GINSTI (Ed.). Constituent Structure. Foris Publications. p. 332-349, 1988.

TARALLO, F.; KATO, M. A. Harmonia trans-sistêmica: variação intra- e interlingüística. Preedição, 5, UNICAMP: Campinas, 1989.

ZUBIZARRETTA, M. L. The grammatical representation of topic and focus: implications for the structure of the clause. USC, 1995. (Trabalho inédito). 